\title{
Compliance with materiality in G4-sustainability reports by electric utilities
}

\author{
Johannes Slacik and Dorothea Greiling \\ Institute of Management Accounting, Johannes Kepler University Linz, \\ Linz, Austria
}

\begin{abstract}
Purpose - Materiality as an emerging trend aims to make sustainability reports (SR) more relevant for stakeholders. This paper aims to investigate whether the reporting practice of electric utility companies (EUC) is in compliance with the materiality principle of the Global Reporting Initiative (GRI) when disclosing SR.

Design/methodology/approach - A twofold content analysis focusing on material aspects (MAs) is conducted, followed by correlation analysis. Logic and conversation theory (LCT) serves to evaluate the communication quality of documented materiality in SR by EUC.

Findings - The coverage and quality of documented MAs in SR by EUC do not meet the requirements for relevant and transparent communication. Materiality does not guide the reporting practice and is not taken seriously.

Research limitations/implications - Mediocre quality of coverage and communication in SR shows that stakeholders' information needs are not considered adequately. The content analysis is limited in focusing on merely documented aspects rather than on actual performance.

Originality/value - This study considers the quality of communication of documented materiality through the lens of LCT. It contributes to the academic debate by introducing LCT as a viable theoretical perspective for analyzing SR. The paper evaluates GRI-G4 reporting practices in the electricity sector, which, while under-researched is crucial for sustainability. It also contributes to the emerging body of empirical research on the relevance of materiality as a guiding principle for sustainability reporting.
\end{abstract}

Keywords Content analysis, Sustainability reporting, Materiality, Correlation analysis, Global reporting initiative (GRI), Electric utilities, Logic and conversation theory

Paper type Research paper

\section{Motivation and research questions}

Sustainability reporting with its focus on economic, environmental and social sustainability issues (Boiral et al., 2019) or the triple-bottom-line (TBL) (Elkington, 1997) is becoming an institutionalized practice, especially in stock-exchange listed companies (Cho et al., 2015). For sustainability reports (SR), a plethora of global, regional and national guidelines have been developed by standard setters (Lozano and Huisingh, 2011), among which the Global Reporting Initiative (GRI) guidelines are the most widely adopted by organizations across the world (KPMG, 2017). In 2016/2017, more than 93 per cent of the top 250 largest

(C) Johannes Slacik and Dorothea Greiling. Published by Emerald Publishing Limited. This article is published under the Creative Commons Attribution (CC BY 4.0) licence. Anyone may reproduce, distribute, translate and create derivative works of this article (for both commercial \& noncommercial purposes), subject to full attribution to the original publication and authors. The full terms of this licence may be seen at http://creativecommons.org/licences/by/4.0/legalcode 
IJESM 14,3

\section{4}

companies worldwide published an SR, 74 per cent of which were using the version GRI-G4Guidelines allowing for comparison (KPMG, 2017).

However, the credibility and reliability of SR have been repeatedly criticized in literature for being a legitimacy façade or a greenwashing attempt, as well as for its limitations in scope and for being non-transparent (Lock and Seele, 2016; Cho et al., 2015; Gray, 2010). Sustainability reporting is thus criticized as impression management and a marketing endeavor for enhancing a company's image or reputation (Talbot and Boiral, 2018).

To make SR more relevant for stakeholders, the materiality principle, which is a wellestablished but still ambiguous principle in financial reporting, has quite recently emerged as a fairly new content-selection principle in SR (Diouf and Boiral, 2017; Eccles et al., 2012). It suggests that SR should focus and formally communicate to stakeholders those aspects that are material to stakeholders for their decision-making (Calabrese et al., 2016). Materiality thus aims at terminating the current practice of confronting stakeholders with a vast variety of irrelevant information in SR.

In 2013, the GRI-G4 guidelines put stakeholder materiality center stage with the expectation of leading to shorter, more focused reports, thus ultimately giving SR more relevance and greater credibility (Puroila et al., 2016; Unerman and Zappettini, 2014). Materiality "is the threshold at which aspects become sufficiently important that they should be reported" (Global Reporting Initiative (GRI), 2013a). The GRI-G4 guidelines require a list of all material aspects (MAs) and their classification according to relevance (low, medium or high) for internal and external stakeholders. The G4-guidelines suggest that "materiality will make reports more relevant, more credible and more user-friendly [... ] "to better inform markets and society on sustainability matters" (Global Reporting Initiative (GRI), 2013a).

As the integration of materiality into sustainability reporting guidelines is relatively recent, little is known as to whether the high expectations regarding materiality as a catalyst to make SR more relevant have been met. This paper answers the call for research into the adoption of the materiality principle in SR (Puroila et al., 2016; Calabrese et al., 2016; Unerman and Zappettini, 2014; Eccles et al., 2012). The scarce prior empirical studies on materiality in sustainability reporting focus mainly on whether MA is listed in SR. So far, the adoption rate of the materiality principle is not overwhelming, indicating caution against too much optimism concerning materiality (Ferrero-Ferrero et al., 2017; Puroila et al., 2016; Jones et al., 2016a, 2016b; Unerman and Zappettini, 2014).

To advocate the importance of making SR more stakeholder-focused, in particular to the strategically most relevant stakeholders (Comyns and Figge, 2015; Freeman et al., 2004), prior research on materiality uses stakeholder theory as the primary theoretical framework (Ferrero-Ferrero et al., 2017; Puroila et al., 2016; Calabrese et al., 2016; Unerman and Zappettini, 2014). While stakeholder theory stresses the importance of focusing SR on stakeholders' information needs, it does not provide criteria for an in-depth stakeholdermateriality analysis of the actual communicative quality of SR, despite the fact that companies are using SR to communicate with their stakeholders. This study seeks to extend previous research by drawing on Grice's (1975) logic and conversation theory (LCT) to facilitate a deeper understanding of the communication quality in SR. LCT has previously been used to analyze accounting reports (Bloomfield, 2008) and legal texts (Slocum, 2016). In theoretical terms, LCT with its four maxims reflecting the quality, comprehensibility and efficiency of communication practices (Röhner and Schütz, 2012) can be seen as complementary to stakeholder theory.

Eccles et al. (2012) suggest that MA should be defined in industry-specific terms. While some sector-specific studies on materiality exist, no studies on materiality in SR in the 
electricity sector have yet been conducted. Electric utility companies (EUC) represent an industry particularly prone to sustainability issues, yet this sector remains under-researched regarding the quantity and quality of sustainability reporting as an instrument of stakeholder accountability. EUCs' economic and political influence, impact and global activities are critically observed by stakeholders - i.e. regulators, politicians, citizens, the media, social and environmental movements, NGOs, as well as employees and unions (Moseñe et al., 2013). The deregulation and privatization of former state monopolies have been accompanied by branding public EUC as inefficient and the establishment of sector regulators. Today, EUC are confronted with economic challenges and investment pressures for adopting climate change technologies, tightening economic and environmental regulations, as well as close scrutiny from competition watchdogs. EUC are still among the largest users of fossil fuels and among the largest greenhouse gas emitters. Therefore, they are under pressure to assume an important role in counteracting the negative consequences of climate change and to contribute to the ambitious de-carbonization objectives of national programs following the 2015 Paris Agreement (Traxler and Greiling, 2018). EUC are consequently facing the challenge of adopting renewable energy and carbon-neutral technologies while securing electricity supply and being financially sustainable (Moseñe et al., 2013; Bakhtina and Goudriaan, 2011; González González, 2010). EUC, therefore, requires extensive sustainability concepts, particularly, as the sector has immense potential for contributing to TBL-developments while simultaneously being associated with negative environmental impacts. Stakeholders demand TBL-accountability, and therefore, the provision of financial and non-financial information from EUC (Moseñe et al., 2013). EUC are publishing voluntary SR in the effort to increase transparency (Fernandez-Feijoo et al., 2014) and to improve public reputation (Moseñe et al., 2013). With respect to sustainability reporting guidelines, EUC warrant close study inasmuch as GRI provides a sector-specific supplement that aims to "[...] cover key aspects of sustainability performance that are meaningful and relevant to the Electric Utility sector and which are not sufficiently covered in the [...]" sector neutral guidelines (Global Reporting Initiative (GRI), 2013b, p. 3).

Based on the research gap identified with respect to materiality in SR by EUC, this paper addresses the following research question $(R Q)$ and sub-questions (SQs):

$R Q$. How is materiality documented in SR by EUC?

- SQ1: What are stakeholders-MA documented in GRI-G4 SR by EUC?

- SQ2: How are identified MA covered in SR by EUC?

- SQ3: How is the communication quality of documented MA in SR by EUC?

To address SQ1, MA documented in materiality matrices in all GRI-G4-SR by EUC listed in the GRI database between 2013 and the end of 2017 are analyzed. To answer SQ2, the coverage rates of all identified MA are studied via quantitative and qualitative content analyses, followed by correlation analysis between the coverage rates of MA and stakeholder relevance. Finally, SQ3 focuses on evaluating the communication quality of reported MA.

Thus, this study analyzes MA for the highly relevant electricity sector and furthermore identifies the extent of coverage and communication quality of documented MA in SR by EUC. To achieve these aims, LCT is introduced as a theoretical framework to analyze and explain the communication quality in SR. The remainder of the paper is structured as follows: Section 2 provides a very brief overview of prior empirical studies and introduces the theoretical approach. Section 3 presents the empirical research 
IJESM 14,3

methods, followed by a presentation of the findings in Section 4. The discussion and conclusion are found in Section 5, covering contributions, research limitations and directions for future work.

\section{Prior empirical studies and theoretical background}

\subsection{Prior studies on materiality as reporting principle for sustainability reports}

Previous literature on materiality as a content principle for GRI-SR from 2000 to 2019 indicates that materiality in SR has scarcely been researched but for a few specific sectors. In total, 20 relevant papers were identified and clustered as follows:

Firstly, three studies found that the user information demands of strategically relevant external stakeholders are not adequately addressed in SR (O'Dwyer et al., 2005; De Villiers and van Staden, 2010; Diouf and Boiral, 2017).

Secondly, 17 studies addressed ways of identifying and selecting stakeholder-MA. These can be distinguished into two groups as follows: those evaluating the documentation process of materiality across industries (Eccles et al., 2012; Puroila et al., 2016; Boiral et al., 2019) and those focusing on a sector (Hsu et al., 2013; Unerman and Zappettini, 2014; Calabrese et al., 2015; Jones et al., 2015a, 2015b, 2016a, 2016b, 2016c; Calabrese et al., 2016; Font et al., 2016; Ferrero-Ferrero et al., 2017; Lai et al., 2017; Guix et al., 2018; Rashidfarokhi et al., 2018). The studies in the latter cluster analyze whether and to what extent SR provide a list of MA and how sector-specific these lists are. A central finding of these studies was that the listed MA are imbalanced, selective and driven by the SR preparers' interests rather than the interests of strategic relevant stakeholders. Sectors analyzed by these studies are the university, banking, cruise ship, building, real estate, hospitality and industry sector. A common finding in this cluster is that the specifics of the respective sectors are not sufficiently accounted for. The implementation of materiality in SR is still in its very early days, and therefore, far from being an institutionalized practice. Some authors regard insufficient documentation and lack of focus on MA in SR as a new frontier for creating an idealized company image through selective reporting and under-reporting negative aspects (Puroila et al., 2016; Ferrero-Ferrero, et al., 2017; Font et al., 2016; Unerman and Zappettini, 2014). With respect to stakeholder accountability, Puroila et al. (2016) conclude that materiality is mostly used to deliberately create a specific image of a company's sustainability performance and call for a reframing of materiality toward a more holistic approach to stakeholder accountability.

\subsection{Prior studies on sustainability reports by electric utility companies}

Previous research on SR by EUC indicates the need for improvement. Existing studies on SR by EUC have so far mainly concentrated on analyzing environmental reporting (Cormier and Gordon, 2001; Freedman and Stagliano, 2008; Alrazi et al., 2010, 2016; Silva-Gao, 2012; Meyer and Pac, 2013; Chang, 2013; Moseñe et al., 2013; Alrazi, 2014; Bae, 2014; Bahari et al., 2016; Talbot and Boiral, 2018; Kraft, 2018), have focused on specific aspects of GRI reporting or have evaluated only the quantitative coverage rates in SR (Gallego, 2006; Alrazi et al., 2010, 2016; Bakhtina and Goudriaan, 2011; Roca and Searcy, 2012; Moseñe et al., 2013; Alrazi, 2014; Camargos et al., 2014; Bahari et al., 2016; Garcia et al., 2016; Sartori et al., 2017; Kraft, 2018; Traxler and Greiling, 2018).

Only four studies address all TBL dimensions of sustainability (Gallego, 2006; Ng and Nathwani, 2012; Traxler and Greiling, 2018; Wu et al., 2018). Nine studies focus on SR by EUC in single countries, especially the USA and European countries (Cormier and Gordon, 2001; Van der Laan Smith et al., 2005; Gallego, 2006; Freedman and Stagliano, 2008; 
Roca and Searcy, 2012; Silva-Gao, 2012; Meyer and Pac, 2013; Moseñe et al., 2013; Bae, 2014), and five studies cover SR by EUC globally (Alrazi et al., 2010, 2016; Kraft, 2018; Talbot and Boiral, 2018; Traxler and Greiling, 2018). However, the samples sizes used in these studies are generally small, except of two studies with samples of 320 and 90 EUC, respectively, focusing on environmental performance (Meyer and Pac, 2013; Bahari et al., 2016) and a recent study by Traxler and Greiling (2018), which analyzes all three dimensions in SR of 84 EUC. The latter shows that the disclosure rates of GRI-G4 indicators amount to 53 per cent and that the coverage of sector-specific indicators is lagging behind the coverage rates of general disclosure indicators. Stock-exchange-listed EUC had higher GRI compliance rates than those in public ownership, despite the higher accountability demands on public EUC (Garcia et al., 2016; Bahari et al., 2016; Fernandez-Feijoo et al., 2014; Traxler and Greiling, 2018).

In sum, the empirical analysis of sustainability reporting practices of EUC has so far focused mainly on specific TBL dimensions, first and foremost the environmental dimension or has concentrated on quantifying the coverage rates in terms of sustainability reporting guidelines. While the focus on GRI in literature is growing, no previous study has addressed compliance with the GRI-materiality principle or the communication quality of SR by EUC.

\subsection{Logic and conversation theory}

Despite the use of SR as a communication tool, neither SR nor materiality has been addressed through the lens of communication theories. To contribute to a refined theoryand method-driven analysis of documented MA in GRI-G4 reports, this research introduces Grice's (1975) LCT as a new perspective in SR research and as a complement to stakeholder theory (Figure 1). Bloomfield (2008) already drew on Grice's maxims for evaluating the flexible formal communication of voluntary accounting reports. LCT is also commonly used for analyzing the literal meaning of legal texts for its quality and comprehensibility (Slocum, 2016). Thus, the analogous use of LCT for analyzing SR by EUC as specific text for communicating with stakeholders seems well justified.

Grice (1975) established four maxims for formal or natural communication that is constructive, transparent, and comprehensible. He argues that informal and formal language is characterized by linguistic patterns, codes, and symbols with divergent meanings that need to be clarified with the help of pragmatic principles such as his four

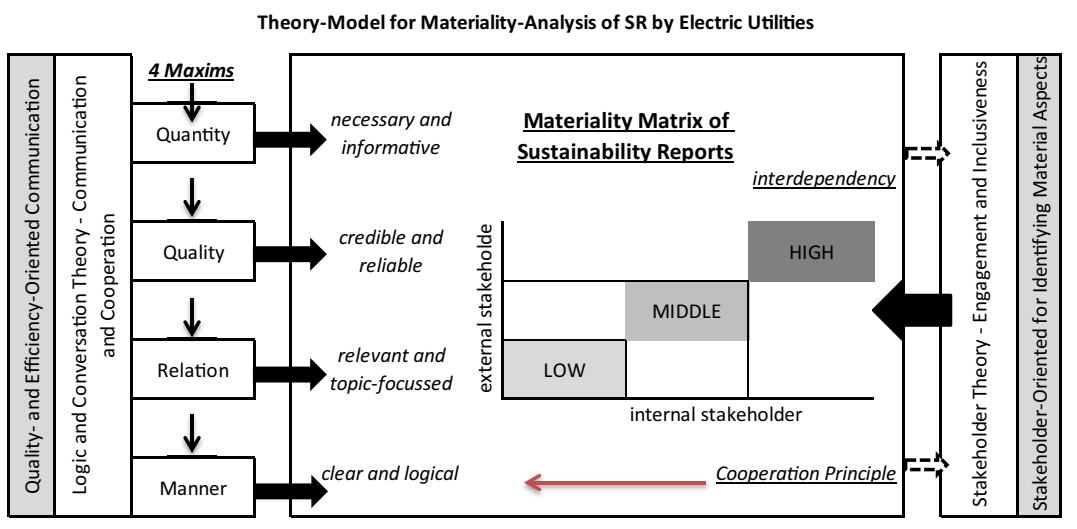

Figure 1. Theory-model for materiality-analysis of SR by EUC 
IJESM

14,3

maxims. He claims that "formal devices (like SR) possess a decisive advantage over their natural (informal)" counterparts, as it is easier to recognize patterns and apply decision procedures to formal language (Grice, 1975, p. 41). Hence, LCT allows analyzing the quality and efficiency orientation of formal communication (Röhner and Schütz, 2012; Bloomfield, 2008) based on four maxims, i.e. quantity (coverage), quality (comprehensibility), relation (relevance) and manner (transparency) (Grice, 1975), as shown in Figure 1.

The quantity-maxim refers to the coverage of all documented indicators necessary to cover stakeholder information needs. The quality-maxim addresses the comprehensibility of texts and allows researchers to investigate the credibility and reliability of documented information. The relation (relevance)-maxim evaluates the amount and detail (topic-focus) of disclosed information and whether it appears as relevant, e.g. by documenting information in dedicated sections or chapters. Finally, the manner (transparency)-maxim evaluates the clarity, understandability and logical description of documented information (Section 4 for methodological use and examples). The key benefit of Grice's approach is the illustration of facts and constraints in texts, thus showing the semantic consequences for communication quality (Wilson and Sperber, 1981).

Unlike other communication theories, Watzlawick et al. (1967) or Shannon and Weaver (1949), LCT includes indicators for relevance and transparency. The evaluation criteria of LCT are suitable for evaluating formal material, in this case, SR. Thus, the four maxims (quantity, quality, relation and manner) can, taken together, serve as guidelines for defining necessary criteria for communication quality to evaluate the content of stakeholder communication in SR. The violation of any of the maxims, e.g. lack of coverage of relevant aspects, unfounded claims, disclosure of irrelevant information or unclear and confusing communication of MA, leads to communication inefficiencies and is thus a source for misunderstanding on the part of the stakeholders (Röhner and Schütz, 2012).

Additionally, LCT entails the "cooperation principle" (Grice, 1975), which comprises two guidelines:

(1) mutually accepted goals of interactions on both sides of the communicating parties (Adler and Rips, 2008). In the context of this paper, this is the documented stakeholder-MA in SR based on stakeholder engagement; and

(2) the actual moment of the conversation (timeliness).

The principle requires acknowledging the stakeholder engagement process for SR by defining which communication parameters are necessary for quality while also addressing the timeliness of the agreed-upon information exchange. However, Bloomfield (2008) suggests that a noncooperative principle may be at work in accounting reports, as practices of selective obfuscation or "cherry picking" seem to deviate from the cooperative principle by making "good news easy to find and bad news hard to find" (Li, 2008) or "not mentioning a topic unless it looks worse by being silent” (Verrecchia, 1983). However, Bloomfield did not consider stakeholder engagement as a GRI content principle and norm for identifying MA. Hence, this study is informed by the cooperative principle in its aim of identifying stakeholder MA. LCT corresponds to the materiality focus using its principle and maxims as guidelines for evaluating the communication quality in SR by EUC. Meeting stakeholder's disclosure demands of MA in accordance with the criteria for communication quality defined by LCT would constitute a substantial step toward stakeholder compliance and taking the materiality demands of stakeholders seriously. 
For this research, SR of 489 energy companies were retrieved from the GRI database providing a full census of English or German GRI SR uploaded until December 31, 2017, in the sector "energy and energy utilities." Regarding the report type, only GRI-G4 reports were considered. Prior GRI versions were excluded because they did not have the same strict requirements for materiality. Of these, merely $186 \mathrm{SR}$ by EUC worldwide could be included for further analysis. A total of 303 uploaded reports had to be excluded because they were reports of the oil and/or gas sector or were not available in the two target languages.

To address SQ1, a qualitative structured content analysis was carried out. The indicators G4-24 to G4-27 document the stakeholder engagement process and are necessary for identifying MA. Indicators G4-17 to G4-23 (materiality) requires documentation of identified MA and their aspect-boundaries. GRI recommends documenting the MA in a stakeholderaccountability-materiality-mix-matrix, which includes a classification of the stakeholderrelevance levels. Out of $186 \mathrm{SR}$ of EUC, 108 used a materiality matrix. Each matrix provides information in terms of three levels of relevance $(1=$ low relevance, $2=$ medium relevance and 3 = high relevance) for internal and external stakeholders. EUC without a materiality matrix were excluded because this would have led to a much higher degree of subjectivity because of the less structured documentation.

To assess materiality in SR by EUC, MA of internal and external stakeholders (based on the materiality matrices) were selected and categorized. MA was first grouped into standard disclosures (SD) of the sector-neutral GRI-G4 guidelines and sector-specific disclosures specified in the GRI electric utility sector supplement. The latter were further subdivided into the three TBL dimensions (economic, environmental and social). Thereafter, MA was categorized by means of deductive categorization, by first creating categories, then setting category examples and coding those, based on Miles et al. (2013), to extract content information from SR. Additionally, material categories not mentioned in the G4-guidelines were complemented by means of induction.

Furthermore, all MA-categories of the 108 SR were aggregated to establish a generalizable umbrella-materiality-matrix, identifying the sum of most important indicators for internal and external stakeholders of EUC.

To answer SQ2, the coverage of all indicators (SD and specific TBL disclosures), as grouped into the MA categories identified in all $108 \mathrm{SR}$, was analyzed via quantitative content analysis. A total coverage rate (TCR) was calculated for each material category. For instance, the material category "energy" has six indicators, i.e. EN3-EN7 and DMA11. If EUC No. 1 reports three out of these six indicators, the compliance level is 50 per cent. The compliance levels were divided into four categories for SPSS-coding $(0=$ no coverage, $1=$ low coverage, $2=$ medium coverage and $3=$ high coverage). The compliance levels are classified as follows: no coverage $=0,>0$ to $<=33.33$ per cent $=1,>33.33$ to $<=66.66$ per cent $=2$ and $>66.66$ per cent $=3$. Thus, the category "energy" shows on average 58 per cent for all 108 SR. If the relevance level for MA "energy" is medium ( 2 or $>33.33$ and $<=66.66$ per cent), the coverage of indicators meet the information needs of stakeholders.

Following this, a correlation analysis was performed to measure the correlation between the documented stakeholder-relevance levels of MA and the TCR of MA in SR. The G4implementation manual recommends that MA of high reporting relevance should be reported in detail; those with a medium priority should be considered for inclusion; and information with a low reporting priority are candidates for the exclusion (Global Reporting Initiative (GRI), 2013c). The correlation coefficient of Spearman was used for interpreting the results. If the $p$-value is under the significance level of 0.05 , the null-hypotheses are rejected 
IJESM

14,3

590 and a correlation between the two groups exists. A positive correlation means that the reporting of the specific material category is aligned with the respective relevance level.

To address SQ3, Grice's four maxims needed to be matched with the criteria of the GRIG4 guidelines, resulting in 12 definition indicators for operationalizing the four maxims for measuring SR content and its boundaries or cut-off criteria (violations) for the maxims (Figure 2). These indicators are used to analyze the communication quality of SR along with the criteria for quality- and efficiency-oriented communication according to LCT.

\subsection{Quantity}

The quantity indicators summarize the identified coverage rates of MA and corresponding disclosure on management approaches (DMAs). Boundaries (violations) of this maxim would be either too few or too many reported indicators (Appendix 1, which provides a coding guideline for all maxims).

\subsection{Quality}

The quality indicators evaluate the comprehensibility of materiality matrices and stakeholder engagement, as well as the balance, comparability, accuracy, timeliness, clarity, and reliability of documented MA and corresponding DMAs. They also include an analysis of whether information on MA is disclosed in dedicated sections or chapters and are described. The indicators also evaluate the credibility and reliability of material information. Boundaries of the quality-maxim are incomprehensibility or insufficient documentation of

\begin{tabular}{|c|c|c|c|}
\hline & & $\begin{array}{l}\text { I\# = Indicator Number } \\
\text { DMA = Disclosure on Management Approach }\end{array}$ & $\begin{array}{l}\mathrm{SD}=\text { Standard Disclosure }(\mathrm{s}) \\
\mathrm{MA}=\text { Material Aspects }\end{array}$ \\
\hline Maxims & I\# & Definition-Indicators & Boundaries \\
\hline \multirow{3}{*}{ Quantity } & \multirow{2}{*}{1} & Coverage of Standard Disclosures & \multirow{3}{*}{$\begin{array}{l}\text { less than } 66,67 \% \text { coverage of } \\
\text { reported indicators of SD, MA } \\
\text { and DMA } \\
\text { too less or too much reported } \\
\text { based on TCR }\end{array}$} \\
\hline & & $\begin{array}{l}\text { Coverage of G4-17 - } 23 \text { Material Aspects and G4-24 - } 27 \\
\text { Stakeholder Engagement }\end{array}$ & \\
\hline & 2 & $\begin{array}{l}\text { Coverage of all indicators of Material Aspects (Materiality } \\
\text { Matrix) and their DMA }\end{array}$ & \\
\hline \multirow{6}{*}{ Quality } & 3 & $\begin{array}{l}\text { Comprehensible Materiality Matrix including Material Aspects } \\
\text { that are identifiable and traceable within SR }\end{array}$ & \multirow{6}{*}{$\begin{array}{l}\text { comprehensibility of Materiality } \\
\text { Matrix } \\
\text { reasoning for none disclosure is } \\
\text { not provided } \\
\text { no detailed and/or unassured } \\
\text { reported MA }\end{array}$} \\
\hline & 4 & $\begin{array}{l}\text { Comprehensible Stakeholder Engagement is identifiable and } \\
\text { traceable within SR }\end{array}$ & \\
\hline & \multirow{4}{*}{5} & $\begin{array}{l}\text { (1) Material Aspects should be balanced, comparable, accurate, } \\
\text { timely, clear and reliable }\end{array}$ & \\
\hline & & (2) Each Material Aspect receives its own section (chapter) & \\
\hline & & (3) Each Material Aspect is explained & \\
\hline & & (4) DMA for every Material Aspect is reported & \\
\hline \multirow{4}{*}{ Relation } & 6 & $\begin{array}{l}\text { Only Material Aspects, its DMA and Standard Disclosures are } \\
\text { documented }\end{array}$ & \multirow{4}{*}{$\begin{array}{l}\text { irrelevant, not MA related } \\
\text { information } \\
\text { incidental information or not } \\
\text { identifiable relevance }\end{array}$} \\
\hline & 7 & $\begin{array}{l}\text { Relevant Material Aspects and its DMA should be distinctly } \\
\text { described and reported (own sections or chapters) }\end{array}$ & \\
\hline & 8 & The Materiality Matrix presents all relevant Material Aspects & \\
\hline & 9 & Description of Stakeholder Engagement process & \\
\hline \multirow{3}{*}{ Manner } & 10 & $\begin{array}{l}\text { Materiality Matrix, Material Aspects and its DMA ought to be } \\
\text { transparent }\end{array}$ & \multirow{3}{*}{$\begin{array}{l}\text { blending of MA indicators } \\
\text { unclear and confusing reporting }\end{array}$} \\
\hline & 11 & Stakeholder Engagement ought to be transparent & \\
\hline & 12 & Material Aspects and its DMA are reported simple and clear & \\
\hline
\end{tabular}

Figure 2. Indicator-map for LCT 
the MA (e.g. showing abbreviations or symbols that are not described) or lack of external assurances.

\subsection{Relation}

The relation indicators evaluate whether MA appears relevant in SR, e.g. only MA and their DMAs are reported. Boundaries of this maxim would be inclusion of irrelevant (not material) or incidental information.

G4sustainability reports

\subsection{Manner}

The manner indicators evaluate whether reported MA and corresponding DMAs are described transparently and are articulated in a manner that is simple, logical and understandable for every stakeholder. Boundaries of this maxim would be a blending of MA and a confusing and unclear disclosure.

Inter-coder reliability, applying Bryman and Bell (2011), is excellent (above 90 per cent). One researcher and two research assistants separately analyzed 10 SR based on the 12 definitions and their boundaries, retrieving the same results based on the categories formed by deduction (Miles et al., 2013).

All 12 indicators of communication quality are weighted equally. Results were added up and divided by the number of indicators, providing a new quantitative measure for the quality of reporting practice - the "total average reporting practice" (TARP). Thereafter, results were categorized into low $<33.33$ per cent, medium $>33.33$ per cent but $<=66.66$ and high quality of reporting $>66.66$ per cent, based on relevance categories of stakeholder engagement. Hence, a report showing a TARP of 27 per cent has low communication quality, whereas a report showing 89 per cent TARP has high quality. Finally, the results in percentages (TARP) identify the communication quality and offer insights regarding the reporting practice, information quality, transparency, efficiency and relevance of MA in SR.

\section{Findings}

\subsection{Descriptive analysis}

Findings show that only 58 per cent (108/186 SR) of the sample have a materiality matrix, and 78 SR (42 per cent) do not. While 55 SR of the sample are from European countries, and 53 SR are from the rest of the world. Companies from countries such as Spain (10), Italy and Russia (7) disclose the most SR. Companies from the USA, Brazil and South Korea disclose (6) SR, followed by Thailand (5), Germany and China (4). All other countries show fewer reports (Figure 5). The sample includes reports from 2013 to 2017. The SR around 43 discloses information of the year 2016 or younger, 65 SR are older than 2015.

\subsection{Aggregated material aspects of electric utility companies (sub-question 1)}

The stakeholder-materiality analysis identified 25 material categories. The categorization of stakeholder-MA is aligned with existing GRI categories. As displayed in Figure 3 below, 22 GRI-G4 material categories [four in the economic dimension, seven in the environmental dimension and seven in the social dimension plus two SDs (stakeholder engagement and corporate governance) and two overall categories (electric utilities operational performance and management approach)] were identified. In addition, three categories were identified via inductive category formation (Miles et al., 2013), i.e. technology and innovation, as well as risk management and investor relations. The newly established GRI standard 2016 has already reacted to the lack of these categories in G4 by including them. 
IJESM

14,3

592

The aggregated average level of relevance of the TBL dimensions for both stakeholder groups is presented in Figure 3. The upper part of Figure 3 shows particularly low relevant material categories as follows: "material," "grievance mechanism," "market presence," and "the disclosure of management approaches." Examples for the category of medium relevance are "electric utilities operational performance," "water" or "compliance." Some categories from the social and environmental dimension perform particularly high, i.e. "labor and decent work," "society," "product responsibility," "emission and climate change" and "energy".

Results have to be read together with the bottom part of Figure 3, showing "no," "low," "medium" and "high" relevance of material categories for the two stakeholder groups, thus showing also no-relevance rates. For example, the material category "material" has no

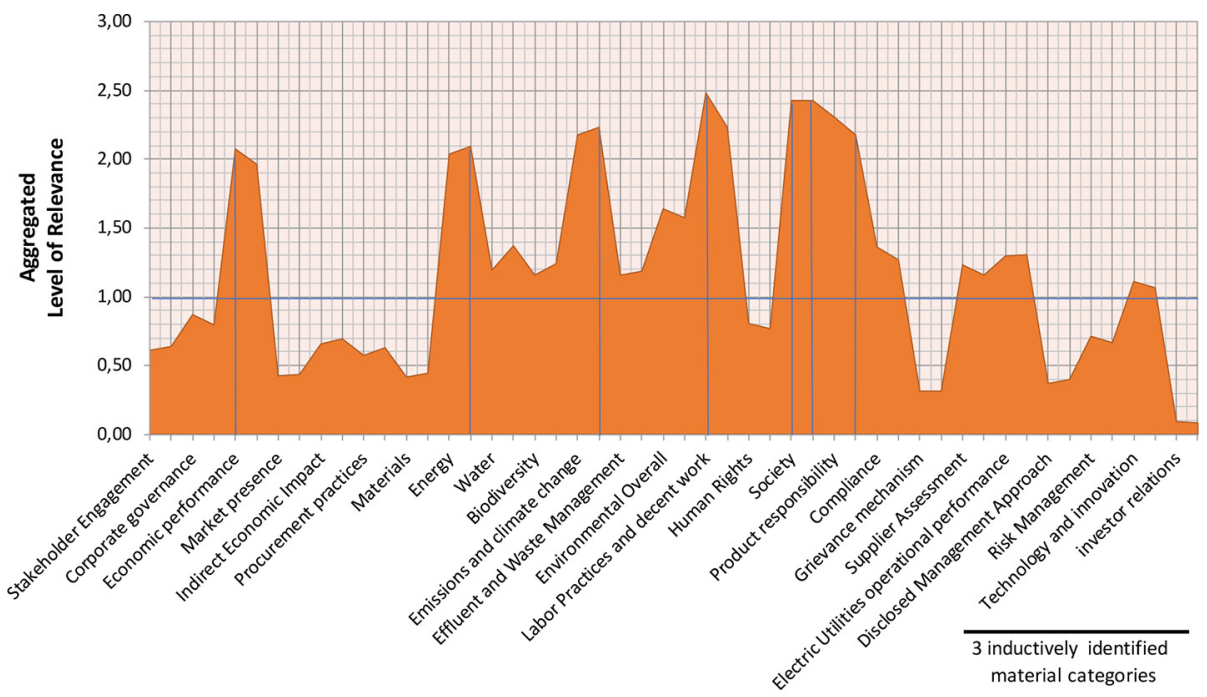

Material Categories of Internal and External Stakeholders of Electric Utilities

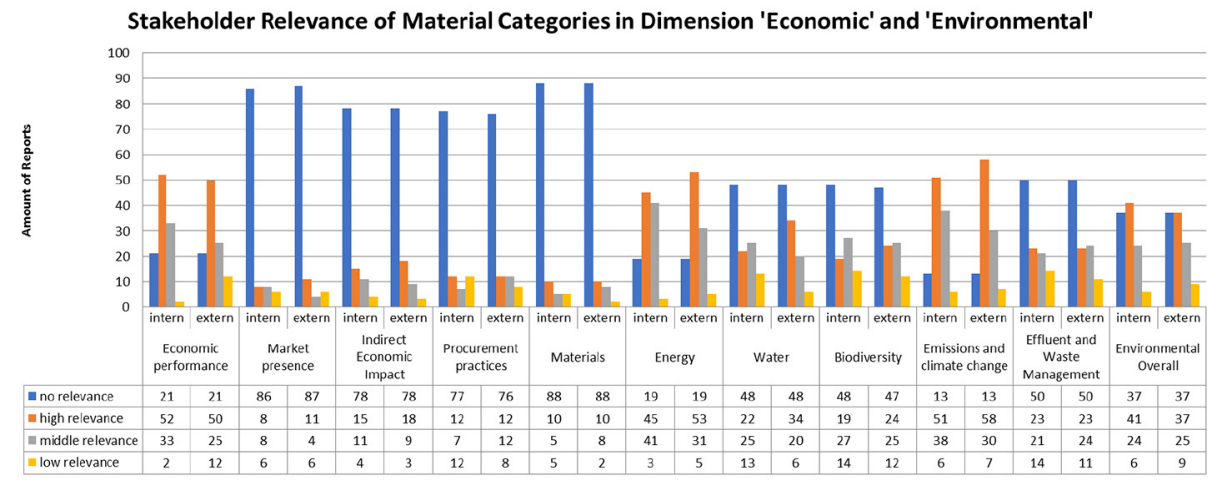

Figure 3.

Stakeholder relevance of material categories in TBL dimensions 
'Social'

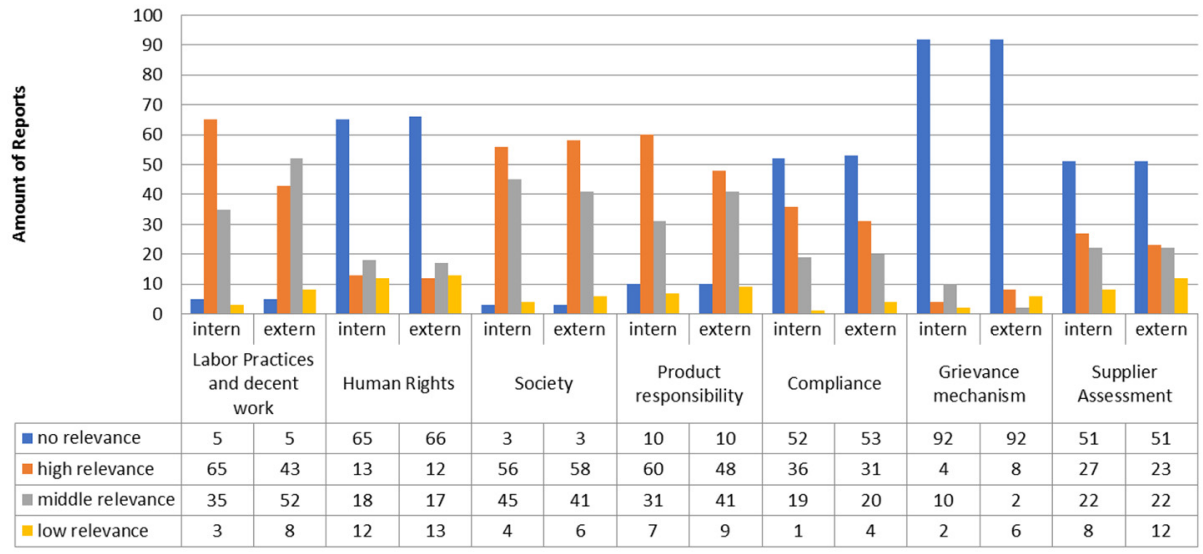

Stakeholder Relevance of Additional Material Categories

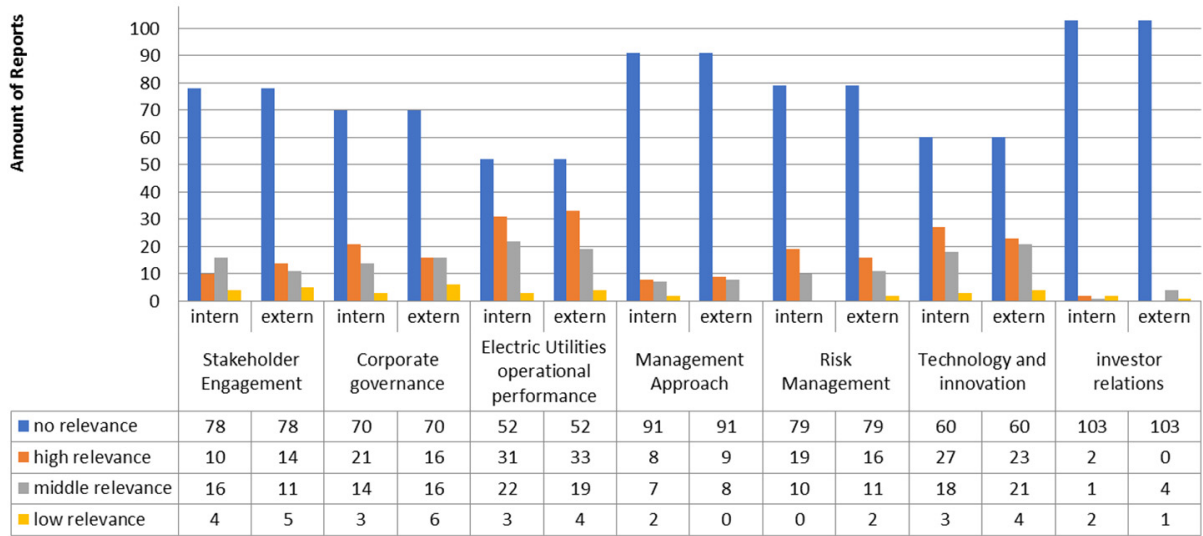

Figure 3.

relevance for both stakeholder groups in 88 EUC. In contrast, "emission and climate change" was not relevant for only 13 EUC.

Furthermore, Figure 3 shows that some material categories clearly have a higher relevance for external than for internal stakeholders and vice versa; hence, reporting expectations do not always match and potentially conflict (e.g. the material category "labor and decent work" is highly relevant in 65 EUC for internal stakeholders but only in 43 EUC for external stakeholders). Similar results are shown for the material category "product responsibility." For the material category "energy," the relevance is higher for external (53) than for internal (45) stakeholders. Similar results are shown for the material categories "water" and "emission and climate change". 
IJESM

14,3

\section{4}

Aggregated findings of all 108 SR are displayed in Figure 4, presenting an umbrellamateriality-matrix that shows internal and external stakeholders-MA and their relevance levels in the electricity sector.

Figure 4 shows that selected categories of the social and environmental dimensions are regarded as highly relevant. The economic dimension varies across all three levels, and most categories of the environmental dimension show a medium relevance.

\subsection{Quantitative coverage of material aspects (sub-question 2)}

Countries like Portugal or Spain show coverage above 70 per cent, while Italy, Hungary, Switzerland, India, USA, Brazil, Australia and Austria only show above 50 per cent. All other countries show even lower coverage in SR, as indicated in Figure 5.

Figure 6 presents the CR of the 22 identified GRI-G4 material categories, including the TCR for the three TBL-dimensions. In sum, the TCR of materiality amounts to 48.1 per cent. Considering that only 58 per cent of the 186 identified EUC provides a materiality matrix, this result is even more unsatisfactory. When adding up the six most relevant material categories, the CR shows merely 54.4 per cent $(64.3+58.2+66.4+55+48.7+33.8 / 6=$ 54.4). It is, therefore, too low for a highly relevant MA, which would have required a minimum average $\mathrm{CR}$ of above 66.6 per cent. A positive outlier is the $\mathrm{CR}$ of stakeholder engagement. The weakest aggregated coverage rate of 39.6 per cent represents the "social" dimension.
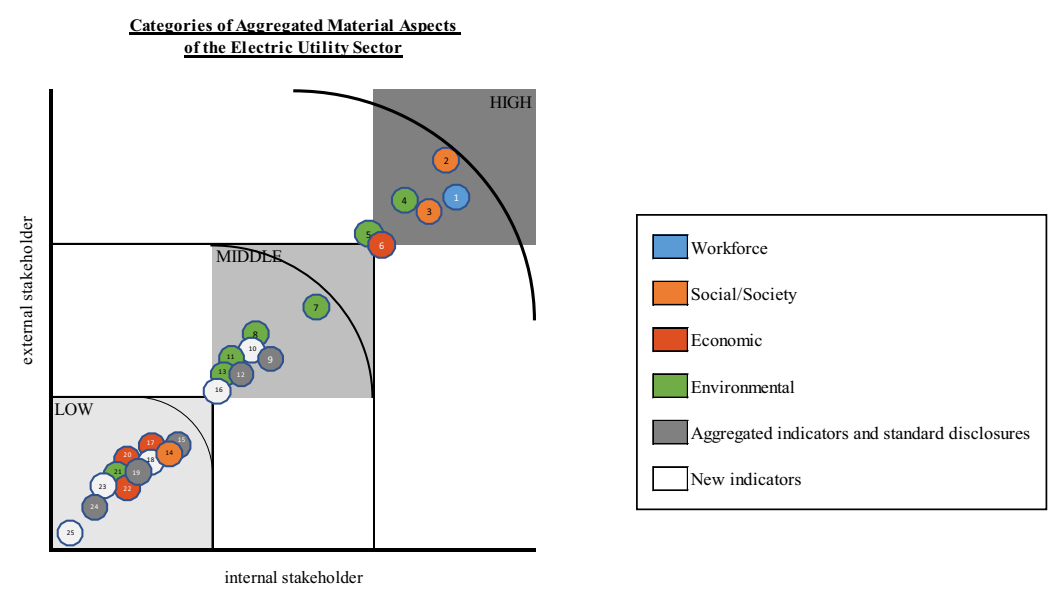

Figure 4. Categories of aggregated MA of EUC

\begin{tabular}{|r|l|}
\hline 1 & Labor practices and decent work \\
\hline 2 & Society \\
\hline 3 & Product responsibility \\
\hline 4 & Emissions and climate change \\
\hline 5 & Energy \\
\hline 6 & Economic performance \\
\hline 7 & Environmental overall \\
\hline 8 & Water \\
\hline 9 & Compliance \\
\hline 10 & Electric utilities operational performance \\
\hline 11 & Biodiversity \\
\hline 12 & Supplier assessment \\
\hline 13 & Effluents and waste management \\
\hline
\end{tabular}

\begin{tabular}{|l|l|}
\hline 14 & Human rights \\
\hline 15 & Corporate governance \\
\hline 16 & Technology and innovation \\
\hline 17 & Indirect economic impact \\
\hline 18 & Risk management \\
\hline 19 & Stakeholder engagement \\
\hline 20 & Procurement practices \\
\hline 21 & Materials \\
\hline 22 & Market presence \\
\hline 23 & Disclosed Management approach \\
\hline 24 & Grievance mechanism \\
\hline 25 & Investor relations \\
\hline
\end{tabular}




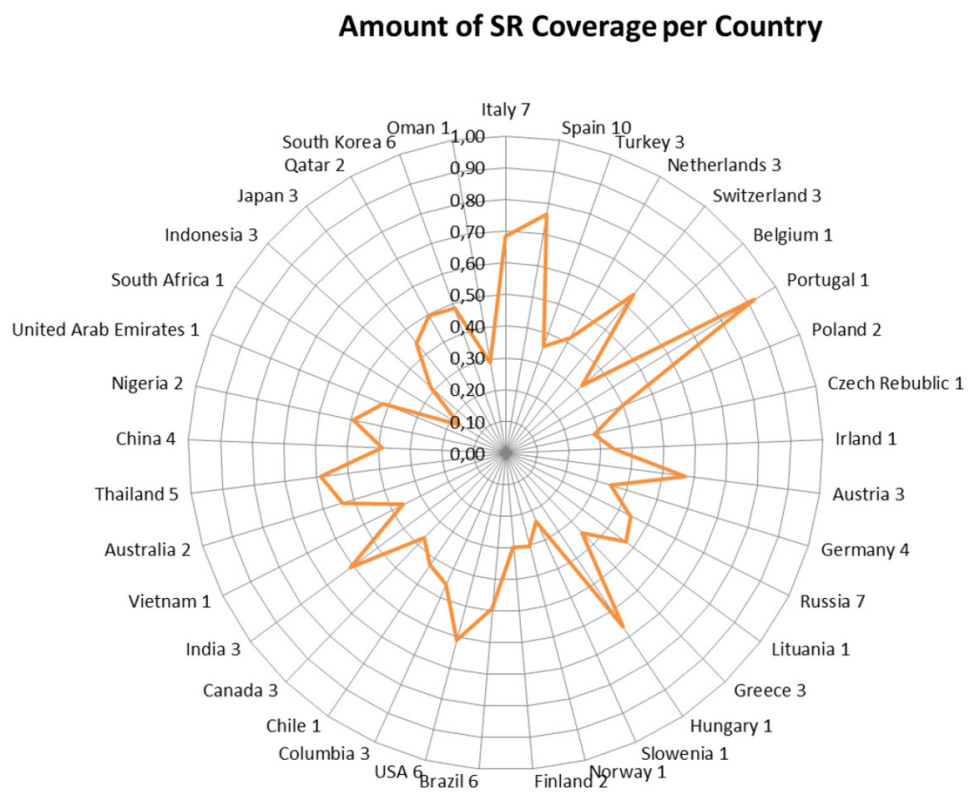

G4-

sustainability reports

595

Average Coverage of 22 Material Categories and TBLDimensions in SR by Electric Utilities

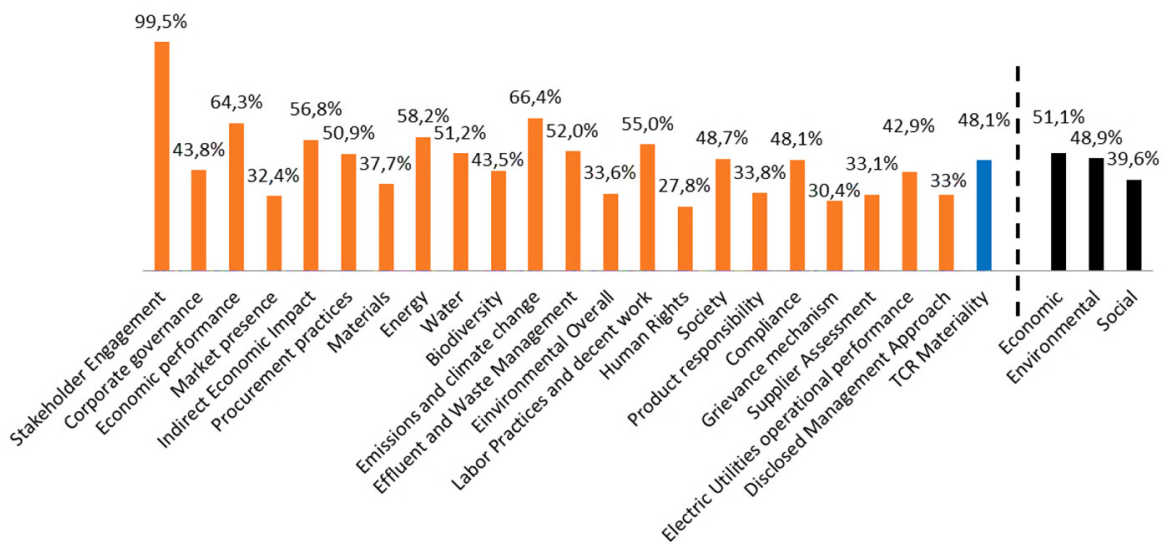

Figure 6.

Average coverage of material categories and TBL dimensions in SR by EUC

Only nine material categories significantly correlate with the TCR of material categories and the internal and external stakeholder relevance in SR. All other categories do not significantly correlate with stakeholder relevance. In eight cases, the results for both stakeholder groups are concurrent. The only exception is the material category "emission and climate change," which is only significant for external stakeholders (Table I). 


\begin{tabular}{|c|c|c|c|c|c|c|c|c|}
\hline \multirow[t]{2}{*}{$\begin{array}{l}\text { 1JESM } \\
14,3\end{array}$} & $\begin{array}{l}\text { Material } \\
\text { categories }\end{array}$ & $\begin{array}{l}\text { TCR } \\
(\%)\end{array}$ & $\begin{array}{l}\text { Internal } \\
\text { stakeholder } \\
\text { rl (mean) }\end{array}$ & $\begin{array}{l}\text { Level of } \\
\text { significance }\end{array}$ & $\begin{array}{c}\text { Correlation } \\
\text { (reliability) } \\
\text { level }(\alpha)\end{array}$ & $\begin{array}{l}\text { External } \\
\text { stakeholder } \\
\text { rl (mean) }\end{array}$ & $\begin{array}{c}\text { Level of } \\
\text { significance }\end{array}$ & $\begin{array}{c}\text { Correlation } \\
\text { (reliability) } \\
\text { level }(\alpha)\end{array}$ \\
\hline & $\begin{array}{l}\text { Economic } \\
\text { performance }\end{array}$ & 64 & 2.07 & 0.002 & 0.01 & 1.96 & 0.017 & 0.05 \\
\hline \multirow{7}{*}{596} & Materials & 38 & 0.42 & 0.002 & 0.01 & 0.44 & 0.002 & 0.01 \\
\hline & Water & 51 & 1.19 & 0.005 & 0.01 & 1.37 & 0.012 & 0.05 \\
\hline & Biodiversity & 44 & 1.16 & 0.000 & 0.01 & 1.24 & 0.001 & 0.01 \\
\hline & $\begin{array}{l}\text { Emission } \\
\text { and climate } \\
\text { change }\end{array}$ & 66 & 2.18 & \multicolumn{2}{|c|}{ Not significant } & 2.23 & 0.045 & 0.05 \\
\hline & Waste & 52 & 1.16 & 0.018 & 0.05 & 1.24 & 0.039 & 0.05 \\
\hline & Compliance & 48 & 1.36 & 0.021 & 0.05 & 1.37 & 0.045 & 0.05 \\
\hline & $\begin{array}{l}\text { Supplier } \\
\text { assessment }\end{array}$ & 33 & 1.23 & 0.003 & 0.01 & 1.16 & 0.005 & 0.01 \\
\hline \multirow{2}{*}{$\begin{array}{l}\text { Table I. } \\
\text { Correlation analysis } \\
\text { of material categories } \\
\text { and the level of } \\
\text { relevance }\end{array}$} & $\begin{array}{l}\text { Electric } \\
\text { utilities } \\
\text { operational } \\
\text { performance }\end{array}$ & 43 & 1.3 & 0.016 & 0.05 & 1.31 & 0.009 & 0.01 \\
\hline & \multicolumn{8}{|c|}{ Notes: $\mathrm{rl}=$ relevance level; $\alpha=$ alpha } \\
\hline
\end{tabular}

A negative indication of the reporting practice of EUC is that compliance with stakeholders' information needs is lacking for 13 material categories. Moreover, compliance is only achieved in two out of six highly relevant material categories, i.e. "economic performance" and "emissions and climate change." Findings show that the reporting practice of the analyzed EUC is not in line with the GRI recommendation to pay the greatest attention to the highly relevant MA.

\subsection{Communication quality of material aspects (sub-question 3)}

In addition to the quantitative $\mathrm{CR}$, the quality of the content communicated in SR was measured using Grice's maxims and specified indicators. All 12 definition indicators and their boundaries were analyzed both overall and separately for European and global coverage of communication quality (Figure 7), yielding the following results and TARP.

Figure 8 displays the aggregated mean values for the four maxims. The results show that the overall communication quality is mediocre with a TARP of 59.7 per cent for all investigated 108 GRI-SR by EUC worldwide. The bottom part displays specific results for the communication quality indicators, indicating room for improvement for all of them.

\section{Quantity}

The first maxim reaches the highest value of the four maxims with an aggregated value of 73.3 per cent (Figure 8 for final results). In Figure 7, Indicator 1 shows 73.9 per cent coverage for all SD. Indicator 2 shows 98 per cent coverage of the material-SD-indicators. The coverage of all material categories taken together, however, is only 48.1 per cent. The average coverage for the quantity-maxim is calculated as follows: $(0.739+0.98+0.481) / 3=$ 0.733 . 


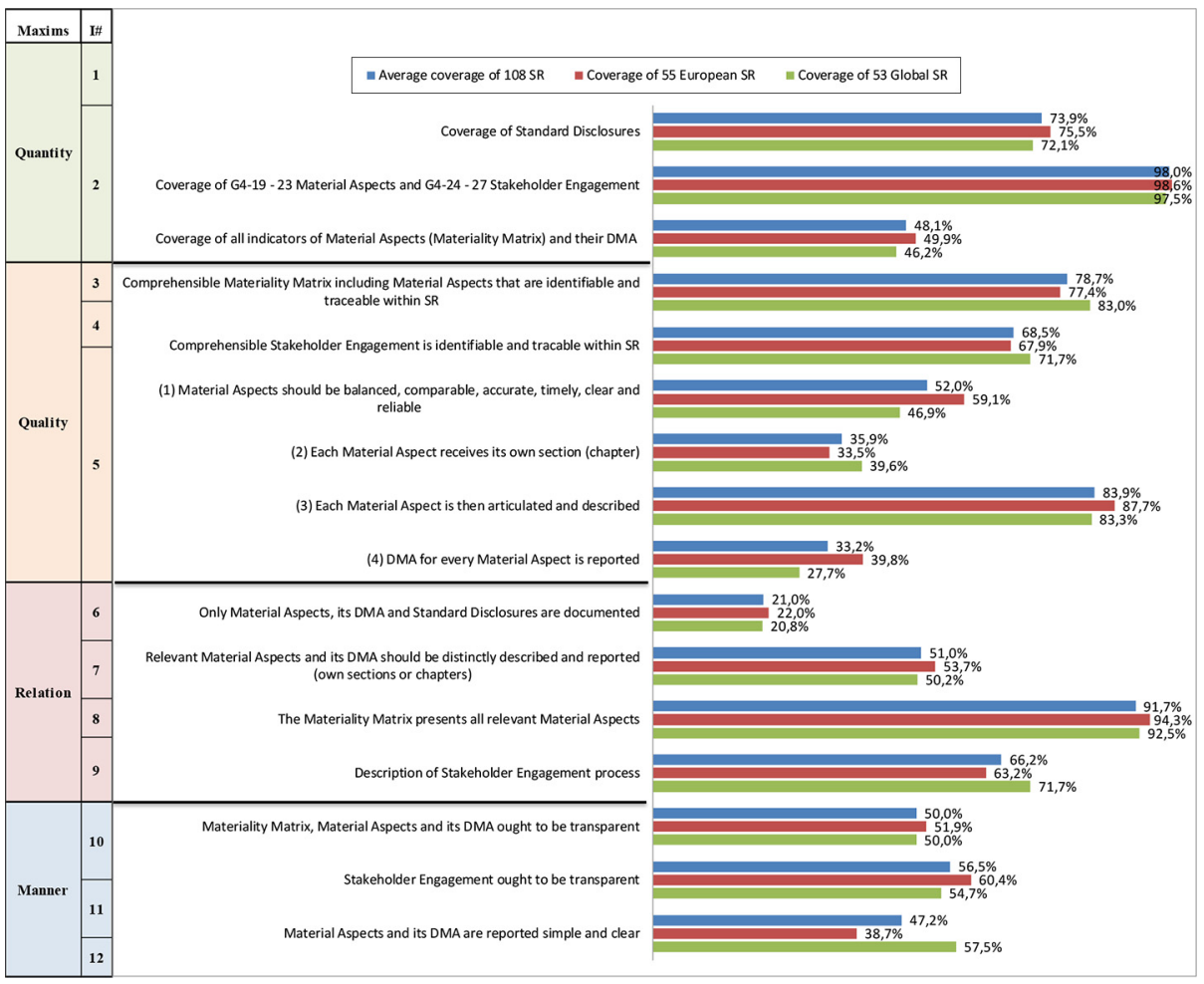

Figure 7.

Coverage of communication quality indicators

\section{Quality}

The aggregated quality of reporting performance is substantially lower at 58.7 per cent (Figure 8). A percentage of 78.7 offers a comprehensible materiality matrix (Indicator 3) and 68.5 per cent of all SR provide comprehensible stakeholder engagement (Indicator 4).

Indicator 5(1) shows a compliance rate of 52 per cent. The sub-results of Indicator 5(1), which are not displayed in Figure 7, are as follows: 53.7 per cent of all reports are balanced (equally addressing positive and negative effects, as suggested by the GRI quality principles); 64.1 per cent are comparable reports; 50.4 per cent include an external assurance certificate; 39.8 per cent are reports from 2016 or newer (timeliness - see Grice's “cooperation principle" and quality principle of GRI-G4 guidelines). With respect to the parameters of Indicator $5(1)$, the reporting quality of 52 per cent is mediocre. This means that 48 per cent of SR are not credible and not reliable in terms of the quality-maxim.

Moreover, Indicator 5(2) shows that only 35.9 per cent document material categories in their own, dedicated sections or chapters. Indicator 5(3) shows that 83.9 per cent of material categories are, however, found somewhere in SR. Moreover, only 33.2 per cent document DMA based on Indicator 5(4). In sum, the mean of quality Indicators 3 and 4 shows that 73.6 per cent are comprehensible, while the mean of Indicator 5 indicates an overall communication quality of only 51.25 per cent. This provides a final result of 58.7 per cent $(78.7+68.5+52+35.9+83.9+33.2=352.2 / 6=58.7)$ for the quality-maxim. 


\section{IJESM \\ 14,3}

\section{8}

Figure 8.

TARP of SR by EUC

\begin{tabular}{|c|c|c|c|c|c|}
\hline \multicolumn{6}{|c|}{ TARP of Material Aspects of Electric Utilities per Maxim } \\
\hline Maxims & Indicators & TARP & $\begin{array}{l}\text { Europe } \\
\text { (TARP) }\end{array}$ & $\begin{array}{l}\text { Global } \\
\text { (TARP) }\end{array}$ & Difference \\
\hline Quantity of coverage & 1,2 & $73.3 \%$ & $74.7 \%$ & $72.0 \%$ & $2.7 \%$ \\
\hline Quality of documentation & $3,4,5$ & $58.7 \%$ & $60.9 \%$ & $58.7 \%$ & $2.2 \%$ \\
\hline $\begin{array}{l}\text { Relation (relevance) of } \\
\text { material aspects }\end{array}$ & $6,7,8,9$ & $57.5 \%$ & $58.3 \%$ & $58.8 \%$ & $0.5 \%$ \\
\hline $\begin{array}{l}\text { Manner (transparency) of } \\
\text { documentation }\end{array}$ & $10,11,12$ & $51.2 \%$ & $50.3 \%$ & $54.1 \%$ & $3.8 \%$ \\
\hline TARP & all indicators & $59.7 \%$ & $61.5 \%$ & $60.3 \%$ & $1.1 \%$ \\
\hline \multicolumn{6}{|c|}{ Selected Information of Communication Quality Results } \\
\hline $\begin{array}{l}\text { Qualitative coverage of } \\
\text { stakeholder engagement }\end{array}$ & $4,9,11$ & $63.7 \%$ & $63.8 \%$ & $66.0 \%$ & $2.2 \%$ \\
\hline $\begin{array}{l}\text { Reported DMAs per } \\
\text { material aspect }\end{array}$ & $5(4)$ & $33.2 \%$ & $39.8 \%$ & $27.7 \%$ & $12.1 \%$ \\
\hline Blended MA and DMAs & 10 & $50.0 \%$ & $51.9 \%$ & $50.0 \%$ & $1.9 \%$ \\
\hline
\end{tabular}

\section{Relation}

The overall mean value for this maxim is 57.5 per cent $(21+51+91.7+66.2 / 4=57.5)$. It is particularly alarming that based on Indicator 6, only 21 per cent of SR content focuses exclusively on MA. Therefore, 79 per cent also disclose non-MA and are not sufficiently focused on stakeholders' information needs. The provision of not relevant information, and therefore, too much information is in strong contrast with the fundamental objective of the materiality principle. A percentage of 51 distinctly describe the documented MA (Indicator 7) and 91.7 per cent present all relevant MA in the materiality matrix (Indicator 8). Regarding Indicator 9, 66.2 per cent of the EUC describes their stakeholder engagement process in detail.

\section{Manner}

Compliance with the manner-maxim is equally mediocre with a mean of 51.2 per cent $(50+56.5+47.2 / 3=51.2)$. Materiality matrices, MA and DMAs are only transparent in 50 per cent of SR (Indicator 10). Transparent stakeholder engagement is provided in only 56.5 per cent of SR (Indicator 11). A simple, understandable description of MA (comprehensible for every stakeholder) is only provided in 47.2 per cent, based on Indicator 12 .

Various blending strategies are used in SR. Sometimes, material categories are mixed in headings, chapters, and texts. In other cases, material categories are mixed with irrelevant information or the indicators of material categories are scattered across different sections of SR. In particular, the blending of several material categories within single chapters in SR tends to be a common practice (see the value for blending in Figure 8).

When summarizing the comprehensibility, relevance, and transparency of stakeholder engagement in SR (by adding indicators $4+9+11$ ), the average communication quality for describing stakeholder engagement is 63.7 per cent. This is far below its CR of 99.5 per cent. Additionally, some reports are evasive because they do not describe the actual stakeholder 
engagement, but rather the TBL progress the respective company has made. Overall, there is a lack of information regarding how MA were gathered in the stakeholder engagement process (e.g. by surveys or interviews). Information on the chosen strategy or process of engagement is also not sufficiently provided or entirely omitted.

In summary, the findings show that only 58 per cent of the SR of EUC has a materiality matrix. All other SR does not provide stakeholder-MA in a structured way. Further results identified 25 material categories. The coverage of material categories is insufficient and the communication quality of those already humble numbers is mediocre. If one combines the results from SQ2 and SQ3, it becomes evident that reporting practice is far from being satisfactory. EUC has embraced the materiality principle not in the ways the GRI-guidelines and prior research recommends for achieving a stakeholder information-need centered SR.

\section{Discussion and conclusion}

This paper analyzes compliance with materiality in SR by EUC, answering the following main RQ: How is materiality documented in SR by EUC? Results show that materiality is still not sufficiently institutionalized as recommended by the GRI-G4 guidelines and prior literature. This result confirms prior empirical studies (Lock and Seele, 2016; Cho et al., 2015).

Regarding SQ1, the large amount of potential MA could be reduced to six highly relevant and seven medium relevant material categories for EUC. This suggests that a focus on MA has the potential to lead to less opulent reports. The umbrella-materiality-matrix (Figure 4) shows that stakeholders are interested in environmental and selected social categories, reflecting that EUC are under close scrutiny for their environmental performance. EUC would, therefore, be well advised to include all highly relevant categories in their reports.

Regarding the findings for SQ2, documented MA based on TBL dimensions are imbalanced with ample room for improvement in all three dimensions of sustainability. The social dimension is particularly underrepresented in SR by EUC. While all EUC claim to report highly relevant MA in their SR, the mediocre CR indicates otherwise. In four out of six highly relevant material categories, there is no sufficient match with stakeholder demands, showing a lack of compliance with stakeholders' information needs. Thus, EUC does not sufficiently comply with the G4-materiality principle. When highly relevant material categories are not reported, the instrumental value of materiality has to be scrutinized, as Burritt and Schaltegger (2010) suggested. The low compliance rate might potentially have adverse effects on the reputation of EUC. If crucial stakeholders (e.g. influential shareholders, regulators, sustainability rating agencies and auditors or CSR investment funds) realize that their information needs are not appropriately met, this can lead to even closer scrutiny in a sector, which is already confronted with critical stakeholders and a sector regulator.

Results regarding SQ3 show that much room for improvement remains for communication quality in SR by EUC. In accordance with the GRI materiality principle, the quantity-maxim proposed by LCT focuses on completeness of covered indicators of exclusively relevant information (MA), necessary for communication quality in SR. However, the mediocre coverage of MA and its DMA violates Grice's quantity-maxim.

Regarding the quality-maxim, stakeholder-MA and its DMA are on average reported below mediocre quality. For example, a lack of documented stakeholder engagement (as the first part of Grice's cooperation principle) is evident, as the reported quality of the stakeholder dialogue is poor. The documentation of the stakeholder engagement process, including all identified stakeholder-MA and their levels of relevance, is insufficient, showing mediocre transparency. EUC fails to take the materiality principle and stakeholder 
IJESM

14,3

engagement seriously, thereby violating the quality-maxim. Some authors have rightly questioned whether stakeholder engagement takes place (Ferrero-Ferrero et al., 2017; Font et al., 2016). Then this still needs to be questioned. On average, EUC fails to disclose balanced information as suggested by GRI-G4 guidelines. Moreover, timeliness of SR (the second part of Grice's cooperation principle and a quality principle of GRI-G4 guidelines) is missed by 65 of 108 SR by EUC, which disclose information older than 2015. The comprehensibility of documented MA is jeopardized by the selective documentation of DMA and the seemingly random appearance of MA in SR, all of which violate the qualitymaxim. While half the reports include external assurance certifications, the credibility and reliability of SR content thus remain questionable. Assurance services may not have effects on the quality of SR expected. Contrary to expectations, materiality has not decreased information asymmetries.

Regarding the relation-maxim, irrelevant information exceeds material information. Reports are overloaded with unnecessary information violating Grice's relation-maxim and thereby also violate the quantity- and manner-maxim. Consequently, MA appears less relevant and less transparent. Transparency and simplicity are lacking, violating Grice's manner-maxim. Furthermore, blending MA with not-MA and irrelevant information is a common reporting practice for EUC, as this study shows. This also constitutes a violation of Grice's manner- and relation-maxim.

In summary, the communication quality is only slightly better than the CR in SR by EUC. However, based on the mediocre TARP, EUC fails to report stakeholder MA in a comprehensible, relevant and transparent way - thus violating Grice's quantity-, quality-, manner- and relation-maxim. The quantity of reported indicators becomes meaningless when the communication quality (TARP) is insufficient. The expectation that materiality will lead to shorter, more focused reports, thereby increasing relevance and credibility of SR, has not been realized. EUC report on documented MA only partially and are, therefore, suspected of "cherry picking." It seems that materiality has not curbed the practice of organizations to concentrate on subjectively chosen aspects. Hence, despite the materiality focus and its valuable potential for stakeholders (Boiral et al., 2019; KPMG, 2017), the adoption of materiality is insufficient. This corresponds to the findings of Puroila et al. (2016), who identified materiality as a way to create an idealized image. Agreeing with the authors, the ambiguity of the materiality principle opens the door for abuse in the form of image creation. Findings suggest that materiality in SR is not adopted satisfactorily and has low influence on the reported content and its communication quality; instead, it serves as a new instrument for disguising, perhaps, even camouflaging and shifting corporate sustainability performances for the better, just as Li (2008) and Verrecchia (1983) pointed out. Violations of all maxims proposed by LCT reveal an overall poor communication quality in SR by EUC, showing low compliance with the materiality principle and stakeholder demands. The high expectations that materiality would lead to more transparency in sustainability reporting seem to have been overly optimistic.

\subsection{Practical implications and contribution}

Consequentially, standard-setters like the GRI could use the identified set of sector-specific material indicators of high and middle relevance to urge EUC to disclose information on these indicators in SR by EUC. This would cut the seemingly arbitrary declaration of MA, leaving less room to pick and choose indicators and more room for detailing sector-specific materiality. Additionally, also EUC could acknowledge the identified sector-specific MAs and aim to cover those in their future SR. EUC could further acknowledge the identified weaknesses and strengths of SR from this study and adjust their reporting accordingly to 
better comply with stakeholder information needs. Finally, lawmakers and sector regulators could read this study as a call to establish and tighten sustainability reporting regulations to assure better coverage of MA and compliance to stakeholder information needs in SR.

This study contributes by having operationalized Grice's maxims for evaluating SR, allowing the identification of TARP in SR. This paper offers an approach for evaluating the communication quality of reporting practice, an aspect overlooked by prior studies that have concentrated exclusively on evaluating CR quantitatively. This extended evaluation approach facilitates a more holistic analysis. This study was able to analyze not only the quantitative $\mathrm{CR}$ but also its communication quality, in a quantitative and qualitative manner. LCT allowed for discovering the overload with irrelevant information and the blended disclosure of MA in SR despite the focus on materiality. This method can be easily adapted for analyzing other forms of company disclosures.

For EUC, the umbrella matrix showing aggregated material categories answers the call by Eccles et al. (2012) for sector-specific materiality frameworks and provides an insight into the most relevant categories for this sector. EUC should include at least the highly relevant sector-specific MA in their future SR for stakeholder and GRI-materiality compliance. Hence, this study could serve as the foundation for further improvements of SR by EUC regarding materiality disclosure.

\subsection{Limitations and future research}

Limitations of this paper are its exclusive focus on the electricity sector and GRI-G4 reports, the exclusion of reports in other languages than German and English, as well as reports without materiality matrices. Moreover, the actual sustainability performance of EUC was not analyzed. Additionally, research on SR by EUC has not yet targeted stakeholder engagement. This study relied on a content analysis based on the GRI-G4 materiality boundaries and stakeholder engagement presented in SR. Hence, a research gap remains regarding the identification of quality and intensity of stakeholder engagement for SR. Furthermore, an in-depth qualitative investigation unveiling possible drivers of the disclosure behavior of EUC might gain new insights from different theoretical perspectives, such as agency theory for uncovering information asymmetries or institutional theory targeting different logics of sustainability reporting.

\section{References}

Adler, J.E. and Rips, L.J. (Eds) (2008), Reasoning: Studies of Human Inference and Its Foundations, Cambridge University Press.

Alrazi, B. (2014), "The carbon disclosure of the Malaysian major power producers: an exploratory study", Journal of Business Management, Vol. 3 No. 2, pp. 12-25.

Alrazi, B., de Villiers, C. and van Staden, C. (2010), "The environmental reporting of electric utilities: an international comparison", 9th CSEAR Australasian Conference, Albury Wodonga, pp. 1-47.

Alrazi, B., De Villiers, C. and Van Staden, C.J. (2016), "The environmental disclosures of the electricity generation industry: a global perspective", Accounting and Business Research, Vol. 46 No. 6, pp. 665-701.

Bae, H. (2014), "Voluntary disclosure of environmental performance: do publicly and privately owned organizations face different incentives/disincentives?", The American Review of Public Administration, Vol. 44 No. 4, pp. 459-476.

Bahari, N.A.S., Alrazi, B. and Husin, N.M. (2016), "A comparative analysis of carbon reporting by electricity generating companies in China, India, and Japan”, Procedia Economics and Finance, Vol. 35 No. 16, pp. 74-81. 
IJESM

14,3

602

Bakhtina, K. and Goudriaan, J.W. (2011), “CSR reporting in multinational energy companies”, Transfer: European Review of Labour and Research, Vol. 17 No. 1, pp. 95-99.

Bloomfield, R.J. (2008), “Accounting as the language of business", Accounting Horizons, Vol. 22 No. 4, pp. 433-436.

Boiral, O., Heras-Saizarbitoria, I. and Brotherton, M.C. (2019), "Assessing and improving the quality of sustainability reports: the auditors' perspective”, Journal of Business Ethics, Vol. 155 No. 3, pp. 703-721.

Bryman, A. and Bell, E. (2011), Business Research Methods, Oxford University Press, Oxford.

Burritt, R.L. and Schaltegger, S. (2010), "Sustainability accounting and reporting: fad or trend?", Accounting, Auditing \& Accountability Journal, , Vol. 23 No. 7, pp. 829-846.

Calabrese, A., Costa, R. and Rosati, F. (2015), "A feedback-based model for CSR assessment and materiality analysis", Accounting Forum, Vol. 39 No. 4, pp. 312-327.

Calabrese, A., Costa, R., Levialdi, N. and Menichini, T. (2016), “A fuzzy analytic hierarchy process method to support materiality assessment in sustainability reporting", Journal of Cleaner Production, Vol. 121, pp. 248-264.

Camargos, M.R., Jannuzzi, G.M. and Gavira, M.O. (2014), "Analysis of the sustainability reporting initiatives of electric utilities in Brazil”, Industrija, Vol. 42 No. 1, pp. 127-147.

Chang, K. (2013), "The effects of ownership and capital structure on environmental information disclosure: empirical evidence from Chinese listed electric firms", WSEAS Transactions on Systems, Vol. 12 No. 12, pp. 637-649.

Cho, C.H., Laine, M., Roberts, R.W. and Rodrigue, M. (2015), "Organized hypocrisy, organizational façades, and sustainability reporting”, Accounting, Organizations and Society, Vol. 40, pp. 78-94.

Comyns, B. and Figge, F. (2015), "Greenhouse gas reporting quality in the oil and gas industry: a longitudinal study using the typology of 'search', 'experience' and 'credence' information", Accounting, Auditing and Accountability Journal, Vol. 28 No. 3, pp. 403-433.

Cormier, D. and Gordon, I.M. (2001), "An examination of social and environmental reporting strategies", Accounting, Auditing and Accountability Journal, Vol. 14 No. 5, pp. 587-617.

De Villiers, C. and van Staden, C.J. (2010), "Shareholders' requirements for corporate environmental disclosures: a cross country comparison", The British Accounting Review, Vol. 42 No. 4, pp. 227-240.

Diouf, D. and Boiral, O. (2017), "The quality of sustainability reports and impression management: a stakeholder perspective", Accounting, Auditing and Accountability Journal, Vol. 30 No. 3, pp. 643-667.

Eccles, R.G., Krzus, M.P., Rogers, J. and Serafeim, G. (2012), "The need for sector specific materiality and sustainability reporting standards", Journal of Applied Corporate Finance, Vol. 24 No. 2, pp. 65-71.

Elkington, J. (1997), “Cannibals with forks”, The Triple Bottom Line of 21st Century Business, Capstone, Oxford.

Fernandez-Feijoo, B., Romero, S. and Ruiz, S. (2014), "Effect of stakeholders' pressure on transparency of sustainability reports within the GRI framework", Journal of Business Ethics, Vol. 122 No. 1, pp. 53-63.

Ferrero-Ferrero, I., Fernández-Izquierdo, M.Á., Muñoz-Torres, M.J. and Bellés-Colomer, L. (2017), "SE in sustainability reporting in higher education, an analysis of key internal stakeholders' expectations", International Journal of Sustainability in Higher Education, Vol. 19 No. 2, pp. 313-336.

Font, X., Guix, M. and Bonilla-Priego, M.J. (2016), "Corporate social responsibility in cruising: using materiality analysis to create shared value”, Tourism Management, Vol. 53, pp. 175-186. 
Freedman, M. and Stagliano, A.J. (2008), "Environmental disclosures: electric utilities and phase 2 of the clean air act", Critical Perspectives on Accounting, Vol. 19 No. 4, pp. 466-486.

Freeman, R.E., Wicks, A.C. and Parma, B. (2004), "Stakeholder theory and the corporate objective revisited”, Organization Science, Vol. 15 No. 3, pp. 364-369.

Gallego, I. (2006), "The use of economic, social and environmental indicators as a measure of sustainable development in Spain”, Corporate Social Responsibility and Environmental Management, Vol. 13 No. 2, pp. 78-97.

Garcia, S., Cintra, Y., Torres, R. de C.S.R. and Lima, F.G. (2016), “Corporate sustainability management: a proposed multi-criteria model to support balanced decision-making", Journal of Cleaner Production, Vol. 136, pp. 181-196.

Global Reporting Initiative (GRI) (2013a), "Sustainability reporting guidelines: reporting principles and standard disclosures", available at: www.globalreporting.org/ (accessed 20 March 2018).

Global Reporting Initiative (GRI) (2013b), "G4 sector disclosures: electric utilities”, available at: www. globalreporting.org/resourcelibrary/GRI-G4-Electric-Utilities-Sector-Disclosures.pdf (accessed 01 October 2018).

Global Reporting Initiative (GRI) (2013c), "Sustainability reporting guidelines: implementation manual", available at: www.globalreporting.org/ (accessed 24 July 2018).

González González, J.M. (2010), "Determinants of socially responsible corporate behaviours in the Spanish electricity sector", Social Responsibility Journal, Vol. 6 No. 3, pp. 386-403.

Gray, R. (2010), "Is accounting for sustainability actually accounting for sustainability . . . and how would we know? An exploration of narratives of organisations and the planet', accounting", Organizations and Society, Vol. 35 No. 1, pp. 47-62.

Grice, H.P. (1975), "Logic and conversation", in Cole, P. and Morgan J. (Eds), Syntax and Semantics, Speech actsVol. 3, pp. 41-58.

Guix, M., Bonilla-Priego, M.J. and Font, X. (2018), "The process of sustainability reporting in international hotel groups: an analysis of stakeholder inclusiveness, materiality and responsiveness", Journal of Sustainable Tourism, Vol. 26 No. 7, pp. 1063-1084.

Hsu, C.W., Lee, W.H. and Chao, W.C. (2013), "Materiality analysis model in sustainability reporting: a case study at lite-on technology corporation”, Journal of Cleaner Production, Vol. 57, pp. 142-151.

Jones, P., Comfort, D. and Hillier, D. (2015a), "Materiality and external assurance in corporate sustainability reporting: an exploratory study of UK house builders", Property Management, Vol. 33 No. 5, pp. 430-450.

Jones, P., Comfort, D. and Hillier, D. (2015b), "Sustainability, materiality, assurance and the UK' s leading property companies a briefing paper for occupiers", Journal of Corporate Real Estate, Vol. 17 No. 4, pp. 282-300.

Jones, P., Comfort, D. and Hillier, D. (2016a), "Materiality in corporate sustainability reporting within UK retailing", Journal of Public Affairs, Vol. 16 No. 1, pp. 81-90.

Jones, P., Comfort, D. and Hillier, D. (2016b), "Managing materiality: a preliminary examination of the adoption of the new GRI-G4 guidelines on materiality within the business community", Journal of Public Affairs, Vol. 16 No. 3, pp. 222-230.

Jones, P., Comfort, D. and Hillier, D. (2016c), "Sustainability in the hospitality industry, some personal reflections on corporate challenges and research agendas", International Journal of Contemporary Hospitality Management, Vol. 28 No. 1, pp. 36-67.

KPMG (2017), "The road ahead, the KPMG survey of corporate responsibility reporting 2017", available at: https:/home.kpmg.com/xx/en/home/campaigns/2017/10/survey-of-corporateresponsibilityreporting-2017.html (accessed 01 November 2017).

Kraft, B. (2018), "Shedding light on stakeholder power in a regulated market: a study of variation in electric utilities' climate change disclosures”, Organization and Environment, Vol. 31 No. 4, pp. 314-338. 
IJESM 14,3

Lai, A., Melloni, G. and Stacchezzini, R. (2017), "What does materiality mean to integrated reporting preparers? An empirical exploration”, Meditari Accountancy Research, Vol. 25 No. 4, pp. 533-552.

Li, F. (2008), "Annual report readability, current earnings and earnings persistence", Journal of Accounting and Economics, Vol. 45 Nos 2/3, pp. 221-247.

Lock, I. and Seele, P. (2016), "The credibility of CSR (corporate social responsibility) reports in Europe: evidence from a quantitative content analysis in 11 countries", Journal of Cleaner Production, Vol. 122, pp. 186-200.

Lozano, R. and Huisingh, D. (2011), "Inter-linking issues and dimensions in sustainability reporting", Journal of Cleaner Production, Vol. 19 Nos 2/3, pp. 99-107.

Meyer, A. and Pac, G. (2013), "Environmental performance of state-owned and privatized Eastern European energy utilities", Energy Economics, Vol. 36, pp. 205-214.

Miles, M.B., Huberman, A.M. and Saldana, J. (2013), Qualitative Data Analysis, Sage.

Moseñe, J.A., Burritt, R.L., Sanagustín, M.V., Moneva, J.M. and Tingey-Holyoak, J. (2013), "Environmental reporting in the Spanish wind energy sector: an institutional view", Journal of Cleaner Production, Vol. 40, pp. 199-211.

Ng, A.W. and Nathwani, J. (2012), "Sustainability performance disclosures: the case of independent power producers", Renewable and Sustainable Energy Reviews, Vol. 16 No. 4, pp. 1940-1948.

O’Dwyer, B., Unerman, J. and Hession, E. (2005), "User needs in sustainability reporting: perspectives of stakeholders in Ireland”, European Accounting Review, Vol. 14 No. 4, pp. 759-787.

Puroila, J., Kujala, J. and Mäkelä, H. (2016), "Reframing materiality in sustainability reporting", Academy of Management Proceedings, Vol. 2016 No. 1, p. 12697.

Rashidfarokhi, A., Toivonen, S. and Viitanen, K. (2018), "Sustainability reporting in the Nordic real estate companies: empirical evidence from Finland", International Journal of Strategic Property Management, Vol. 22 No. 1, pp. 51-63.

Roca, L.C. and Searcy, C. (2012), "An analysis of indicators disclosed in corporate sustainability reports”, Journal of Cleaner Production, Vol. 20 No. 1, pp. 103-118.

Röhner, J. and Schütz, A. (2012), Psychologie Der Kommunikation, Basiswissen Psychologie, Springer Fachmedien, Wiesbaden.

Sartori, S., Witjesb, S. and Campos, L.M.S. (2017), "Sustainability performance for Brazilian electricity power industry: an assessment integrating social, economic and environmental issues", Energy Policy, Vol. 111, pp. 41-51.

Shannon, C.E. and Weaver, W. (1949), The Mathematical Theory of Communication, University of IL Press, Urbana.

Silva-Gao, L. (2012), "The disclosure of environmental capital expenditures: evidence from the electric utility sector in the USA", Corporate Social Responsibility and Environmental Management, Vol. 19 No. 4, pp. 240-252.

Slocum, B.G. (2016), “Conversational implicatures and legal texts”, Ratio Juris, Vol. 29 No. 1, pp. 23-43.

Talbot, D. and Boiral, O. (2018), "GHG reporting and impression management: an assessment of sustainability reports from the energy sector", Journal of Business Ethics, Vol. 147 No. 2, pp. 367-383.

Traxler, A.A. and Greiling, D. (2018), "Sustainable public value reporting of electric utilities", Baltic Journal of Management, available at https://doi.org/10.1108/BJM-10-2017-0337 (accessed 29 November 2018).

Unerman, J. and Zappettini, F. (2014), "Incorporating materiality considerations into analyses of absence from sustainability reporting", Social and Environmental Accountability Journal, Vol. 34 No. 3, pp. 172-186. 
Van der Laan Smith, J., Adhikari, A. and Tondkar, R.H. (2005), "Exploring differences in social disclosures internationally: a stakeholder perspective", Journal of Accounting and Public Policy, Vol. 24 No. 2, pp. 123-151.

Verrecchia, R. (1983), "Discretionary disclosure", Journal of Accounting and Economics, Vol. 5, pp. 179-195.

Watzlawick, P., Beavin, J.H. and Jackson, D.D. (1967), The Pragmatics of Human Communication, Norton, New York, NY.

Wilson, D. and Sperber, D. (1981), "On Grice's theory of conversation”, in Werth, P. (Ed.), Conversation and Discourse: Structure and Interpretation, Croom Helm, London.

Wu, S., Shao, C. and Chen, J. (2018), "Approaches on the screening methods for materiality in sustainability reporting”, Sustainability, Vol. 10 No. 9, p. 3233.

\section{Further reading}

Burritt, R.L. and Schaltegger, S. (2010), "Sustainability accounting and reporting: fad or trend?', accounting", Accounting, Auditing and Accountability Journal, Vol. 23 No. 7, pp. 829-846.

Cho, C.H., Michelon, G. and Patten, D.M. (2012), "Impression management in sustainability reports: an empirical investigation of the use of graphs", Accounting and the Public Interest, Vol. 12 No. 1, pp. 16-37.

Greiling, D., Traxler, A.A. and Stötzer, S. (2015), "Sustainability reporting in the Austrian, German and Swiss public sector", International Journal of Public Sector Management, Vol. 28 Nos 4/5, pp. 404-428.

Hahn, R. and Kühnen, M. (2013), "Determinants of sustainability reporting: a review of results, trends, theory, and opportunities in an expanding field of research", Journal of Cleaner Production, Vol. 59, pp. 5-21.

O'Dwyer, B. and Owen, D. (2007), "Seeking stakeholder-centric sustainability assurance", Journal of Corporate Citizenship, Vol. 25 No. 1, pp. 77-94. 
IJESM
14,3

606

Table AI.

Codification guideline

\section{Appendix 1}

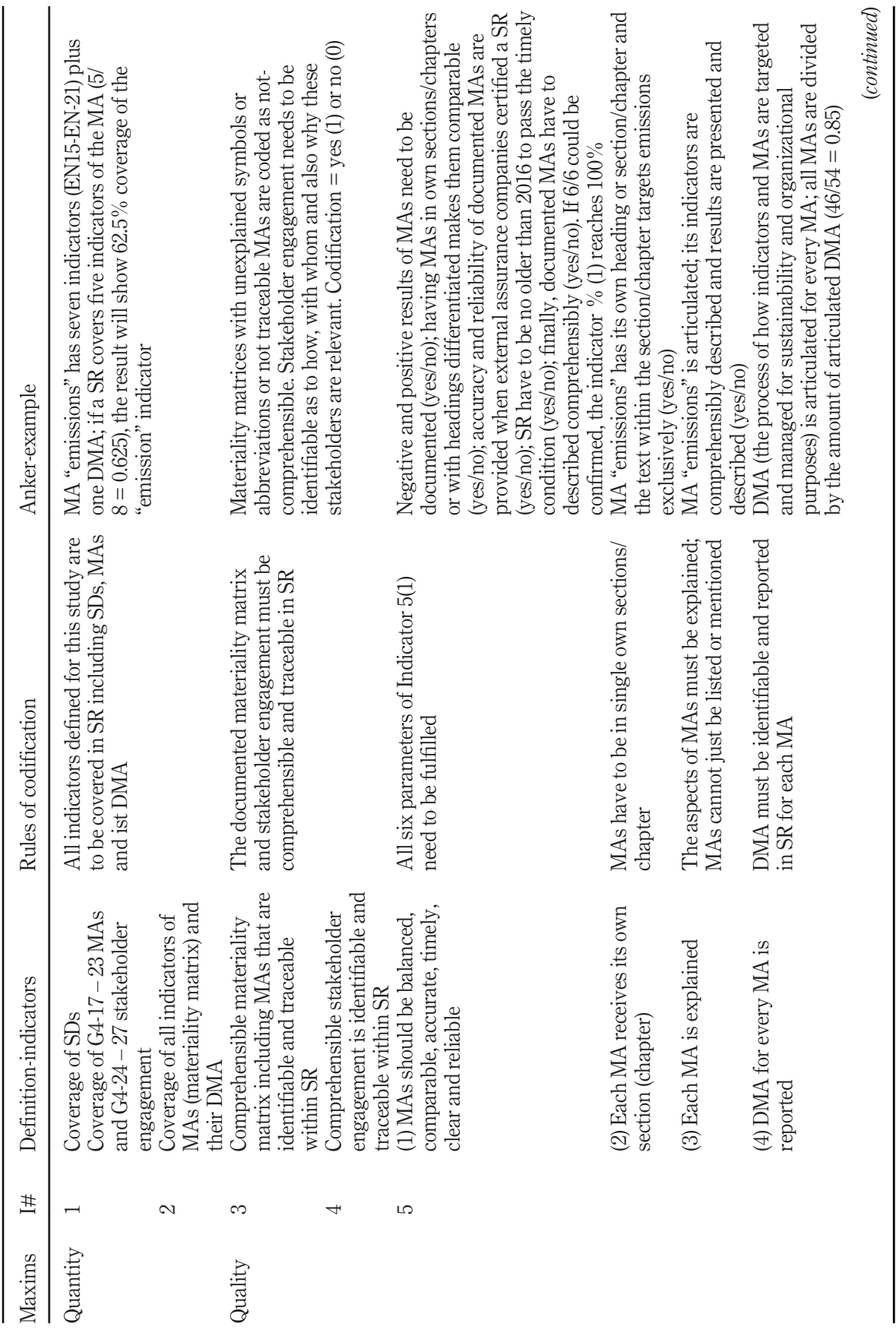




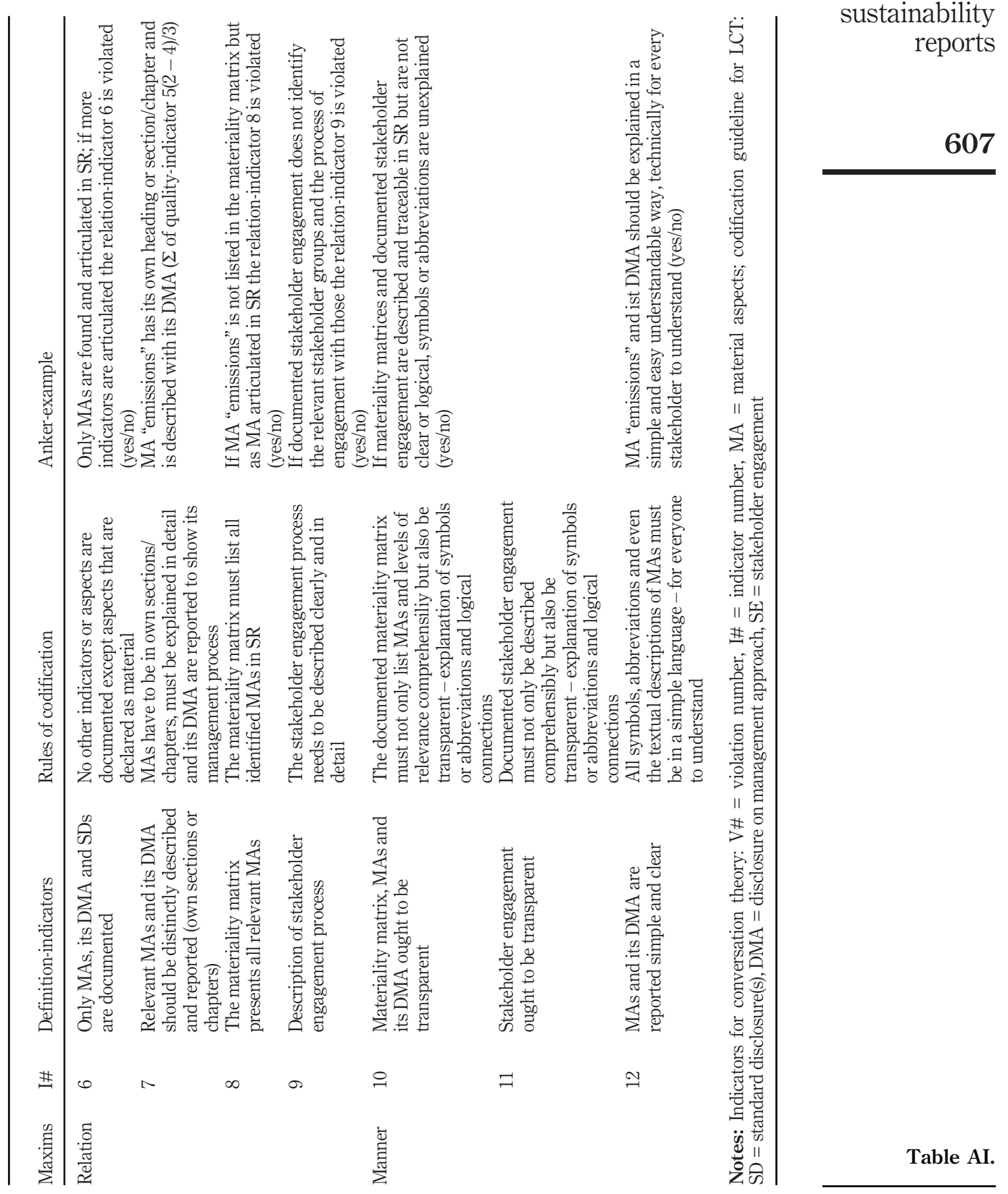




\begin{tabular}{lll} 
IJESM & \multicolumn{2}{l}{ Appendix 2 . List of acronyms } \\
14,3 & DR & = coverage rate(s); \\
DMA & = disclosure(s) on management approach; \\
EUC & = electric utility companie(s); \\
GRI & = Global reporting Initiative; \\
LCT & $=$ logic and conversation theory; \\
$\mathbf{6 0 8}$ & MA & = material aspect(s); \\
RQ & = research question(s); \\
SD & = standard disclosure(s); \\
SQ & = sub-question(s); \\
SR & = sustainability report(s); \\
TBL & = triple-bottom-line; \\
TCR & = total coverage rate(s); and \\
TARP & $=$ total average reporting practice.
\end{tabular}

\begin{abstract}
About the authors
Johannes Slacik studied business economics in 2009, after 20 years of hospitality management practice, and operates since 2013 as a business consultant for leadership and change management. In 2017, Slacik took additionally on a position as associate for research and teaching at the Institute of Management Accounting, Johannes Kepler University (JKU), writing his $\mathrm{PhD}$. His research spectrum focuses on the electric utility sector, sustainability reporting and the implementation of sustainability management control systems. Johannes Slacik is the corresponding author and can be contacted at: johannes.slacik@jku.at

Dorothea Greiling studied business economics in Bamberg und Mannheim, Germany and was 13 years research associate for the Institute for Public and Nonprofit Management, University of Mannheim; 1995 promotion; She was a professor at the University of Darmstadt, Mannheim and is since 2008 head of the Institute for Management Accounting at the Johannes Kepler University (JKU), Linz, Austria. Her research focus is oriented by behavioral management accounting, accountability and sustainability reporting in the public and nonprofit sectors.
\end{abstract}

For instructions on how to order reprints of this article, please visit our website: www.emeraldgrouppublishing.com/licensing/reprints.htm Or contact us for further details: permissions@emeraldinsight.com 